\title{
Retroaortic left renal vein (RLRV) draining into the left common iliac vein: a rare variant and its clinical implication
}

\author{
Fidel Rampersad, ${ }^{01}$ Adrian Chan, ${ }^{2}$ Jason Diljohn ${ }^{3}$
}

${ }^{1}$ Radiology Unit, Department of Clinical Medical Sciences, University of the West Indies, St. Augustine Campus, Trinidad and Tobago

${ }^{2}$ Radiology Department, Port of Spain General Hospital, Port of Spain, Trinidad and Tobago ${ }^{3}$ Radiology Department, San Fernando General Hospital, San Fernando, Trinidad and Tobago

\section{Correspondence to} Dr Fidel Rampersad, fidelrampersad@gmail.com

Accepted 13 April 2019

\section{DESCRIPTION}

A 55-year-old known hypertensive woman with a family history of breast cancer and pancreatic cancer in first-degree relatives was referred by her general practitioner for an intravenous contrast-enhanced multidetector CT (MDCT) scan of her abdomen and pelvis. There was no MDCT evidence of malignancy; however, there was an incidentally detected retroaortic left renal vein (RLRV), coursing obliquely and posterior to the abdominal aorta, draining into the left common iliac vein just prior to the origin of the inferior vena cava (IVC) (figures 1 and 2). The patient gave no history of prior urological symptoms that may be associated with this anomaly.

The RLRV is a rare variant, with an incidence of $0.5 \%-3.1 \% .^{1}$ There are four subtypes of the RLRV which include: (1) type 1, where the RLRV joins the IVC in the orthotopic position; (2) type 2, where the RLRV joins the gonadal and ascending lumbar veins prior to joining the IVC at the level of the fourth to fifth lumber vertebral bodies; (3) type 3 is a RLRV which consists of both anterior and retroaortic left renal veins (circumaortic) prior to joining the IVC and (4) type 4, where the ventral preaortic limb of the left renal vein is obliterated and the dorsal limb persists as a RLRV, coursing obliquely and caudal behind the aorta to join the left common iliac vein. ${ }^{2}$ The patient in this case had the latter, which appears to be the rarest of the four subtypes, with an incidence of $0.16 \%$, and only a few cases documented. ${ }^{2}$

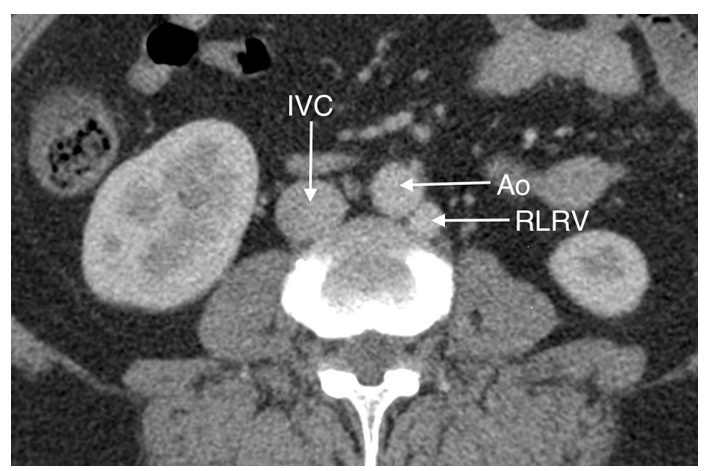

Figure 1 Axial postintravenous contrast CT Image (mixed arterial/venous phased) showing the RLRV coursing left and postero-lateral to the Ao, prior to crossing the midline and draining into the IVC. Ao, abdominal aorta; IVC, inferior vena cava; RLRV, retroaortic left renal vein.

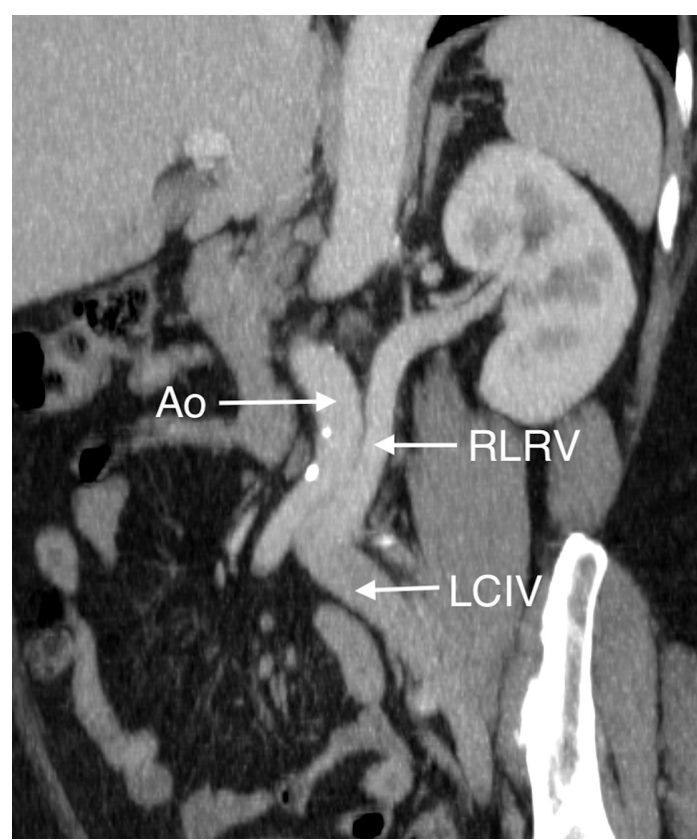

Figure 2 Oblique, coronal, curved multiplanar reformatted, intravenous contrast enhanced, MIP CT image (mixed arterial/venous phase), showing the RLRV located oblique and posterior to the Ao and draining into the LCIV. Ao, abdominal aorta; LCIV, left common iliac vein; MIP, maximum intensity projection; RLRV, retroaortic left renal vein.

The RLRV is usually asymptomatic, as seen in our case; however these patients can present with haematuria, flank pain, scrotal varicocele and pelvic congestion due to the nutcracker syndrome. ${ }^{34}$ Nutcracker syndrome occurs as a result of compression of the RLRV which leads to venous congestion of the left kidney. This results in rupturing of the thin-walled septum between the vessels and the renal pelvis causing microscopic and gross haematuria. Moreover, with passage of small blood clots, flank pain can occur. ${ }^{1356}$ Consequently, congested kidneys and renal infarcts secondary to the vascular compromise may lead to bacterial colonisation and abscess formation. In addition, scrotal varicocele can result from reflux into the left gonadal vein due to the compression of the RLRV with pelvic congestion syndrome occurring in women.

Furthermore, preoperative knowledge of this variant is important to avoid complications associated with vascular injury to the RLRV such as severe haemorrhage, renal injury, nephrectomy 
and even death during retroperitoneal surgery or interventional procedures. $^{7}$

The diagnosis of RLRV and its variant subtypes were previously determined by postmortem analysis. Today, variant anatomy of the left renal vein can be seen on renal venography, colour doppler ultrasonography, MDCT and MRI. ${ }^{6}$ Presently, MDCT is the imaging modality of choice for evaluation of the

\section{Patient's perspective}

My family has a history of cancer. My sister had breast cancer, her breast was removed, and she was good for a few years until she fell sick at the age of 61 . She was then diagnosed with a recurrence of breast cancer and died a few months later. My brother was diagnosed with pancreatic cancer but was treated and is now cured. Following the death of my sister, I was worried that I may be at risk for cancer. I visited my doctor who sent me a for a series of blood tests, mammogram and CT scan. I was told that the mammogram, CT scan and all the other blood tests came back normal but was then informed that I had a variant in my left kidney vein. The doctor explained to me that this was a rare finding and I must inform my doctors on this variant in the event of surgery or if symptoms occur. My main concern was if this was dangerous to my health however the doctor reassured me. I am quite happy, and I like to be aware of what is going on with my body.

\section{Learning points}

- A retroaortic left renal vein is usually asymptomatic; however, patients can present with haematuria, flank pain, scrotal varicocele and pelvic congestion due to the nutcracker syndrome.

- Cross-sectional imaging has replaced invasive conventional angiography and venography as the imaging modality of choice for the diagnosis of vascular variations of the retroperitoneum.

- Preoperative detection of a left renal vein variant can decrease morbidity and mortality associated with injury to this anomalous vessel. kidneys and the retroperitoneal structures, with MDCT angiography/venography being used for the diagnosis of vascular variations. ${ }^{6}$ Furthermore, MDCT has replaced invasive conventional angiography and venography as it is non-invasive, reliable and easily applicable. ${ }^{8}$

In conclusion, the availability of MDCT can aid the diagnosis of left renal vein anomalies detected incidentally, as noted in our case, and also to help delineate and further categorise left renal vein anomalies, hence, reducing the risk of complications associated with injury to this anomalous vessel. Additionally, the presence of left renal vein anomalies may result in symptoms, and the referring physician and radiologist should be aware of them.

Acknowledgements I would like to acknowledge Dr Megan Munro who assisted in editing and formatting the case for final submission.

Contributors FR was instrumental in planning the write-up of this case. He was involved in the interpretation of the images and review of the final submitted document. AC obtained consent from the patient and helped with the write-up of the case. JD also assisted with the case write-up and with the selection of images used in the case.

Funding The authors have not declared a specific grant for this research from any funding agency in the public, commercial or not-for-profit sectors.

Competing interests None declared.

Patient consent for publication Obtained.

Provenance and peer review Not commissioned; externally peer reviewed.

\section{REFERENCES}

1 Kawai K, Tanaka T, Watanabe T. A rare anomaly of left renal vein drainage into the left common iliac vein: A case report. Int J Surg Case Rep 2016:20:4-6.

2 Prakash C, Ali S, Khan SM. Anomalous left renal vein coursing behind aorta and draining into the left common iliac vein: A rare variant. Int J Case Rep Images 2014;5:553-7.

3 Hsieh C-L, Tiao W-M, Chou Y-H, et al. Retroaortic Left Renal Vein: Three Case Reports. J Med Ultrasound 2012;20:115-8.

4 Duran JT, Arquez HF. Anatomical study of retro-aortic left renal vein. J Chem Pharm Res 2016;8:1011-8

5 Mathews R, Smith PA, Fishman EK, et al. Anomalies of the inferior vena cava and renal veins: embryologic and surgical considerations. Urology 1999;53:873-80.

6 Fluckiger TA, Eapen AS, Bhattal GK, et al. Retroaortic left renal vein â developmental and clinical implications. International Journal of Anatomical Variations 2016;9.

7 Bass JE, Redwine MD, Kramer LA, et al. Spectrum of Congenital Anomalies of the Inferior Vena Cava: Cross-sectional Imaging Findings 1: (CME available in print version and on RSNA Link). Radiographics 2000;20:639-52.

8 Karaman B, Koplay M, Ozturk E, et al. Retroaortic left renal vein: multidetector computed tomography angiography findings and its clinical importance. Acta Radiol 2007:48:355-60.

Copyright 2019 BMJ Publishing Group. All rights reserved. For permission to reuse any of this content visit https://www.bmj.com/company/products-services/rights-and-licensing/permissions/

BMJ Case Report Fellows may re-use this article for personal use and teaching without any further permission.

Become a Fellow of BMJ Case Reports today and you can:

- Submit as many cases as you like

- Enjoy fast sympathetic peer review and rapid publication of accepted articles

- Access all the published articles

Re-use any of the published material for personal use and teaching without further permission

For information on Institutional Fellowships contact consortiasales@bmjgroup.com

Visit casereports.bmj.com for more articles like this and to become a Fellow 